\title{
Immunohistochemical localisation of the matrix metalloproteinases MMP-3 and MMP-9 within the airways in asthma
}

Barbro Dahlen, Janis Shute, Peter Howarth

\begin{abstract}
Background-The matrix metalloproteinase (MMP) enzymes MMP-3 and MMP-9 have relevance to the chronic structural airway changes in asthma. These proteinases can be generated by structural and inflammatory cells, and have the ability to degrade proteoglycans and thus potentially enhance airway fibrosis and smooth muscle proliferation through their ability to release and activate latent matrix bound growth factors. Methods-Immunostaining for MMP-3 and MMP-9 as well as for mast cells, eosinophils, and neutrophils was undertaken in acetone fixed and glycolmethacrylate embedded endobronchial biopsy specimens obtained by fibreoptic bronchoscopy under local anaesthesia. The findings from 17 asthmatic subjects (nine with mild to moderate non-steroid treated asthma and eight with chronic persistent steroid-dependent asthma) were compared with those from eight healthy controls. The cell associated MMP immunoreactivity was co-localised to mast cells, eosinophils, or neutrophils and represented as cells $/ \mathrm{mm}^{2}$, based on the area of the biopsy specimen. Extracellular matrix immunoreactivity was assessed by an image analysis system and visually with ranking and the two approaches were compared.
\end{abstract}

Results-The biopsy specimens from asthmatic subjects contained significantly more eosinophils $(p<0.001)$ than those from the non-asthmatic subjects. Both MMP-9 and MMP-3 immunoreactivity could be identified in endobronchial biopsy specimens. Gelatinase B (MMP-9) immunoreactivity was prominent within the extracellular matrix as well as exhibiting distinct cell immunoreactivity which predominantly co-localised to neutrophils. Stromelysin (MMP-3) was colocalised to mast cells, eosinophils, and neutrophils as well as being present in the epithelium, the lamina reticularis and, to a lesser extent, the extracellular matrix. There was no significant difference in the extent of matrix immunoreactivity for either MMP-3 or MMP-9 between healthy controls or subjects with mild or severe asthma.

Conclusion-Although immunostaining cannot distinguish between active and inactive forms of MMPs, the presence of
MMP-3 and MMP-9 within endobronchial biopsy specimens, the co-localisation to inflammatory cells of relevance to asthma (mast cells and eosinophils), and the identification of matrix binding, indicative of MMP-matrix interactions, points to the potential for disease related changes in MMP release that influence airway remodelling in asthma.

(Thorax 1999;54:590-596)

Keywords: matrix metalloproteinases; asthma

The matrix metalloproteinases (MMPs) are a large family of zinc containing enzymes with well conserved common structural domains that exhibit degradative activity against a range of extracellular matrix proteins. ${ }^{1}$ There are four main subclasses: (1) the gelatinases, formerly known as type IV collagenases, which have activity against basement membrane collagens and matrix proteoglycans as well as having gelatinolytic activity; (2) the collagenases which degrade connective tissue collagens; (3) the stromelysins which have broad substrate specificity in degrading extracellular matrix proteoglycans, laminin, fibronectin, elastin and the globular portion of basement membrane collagens; and (4) a membrane bound MMP involved in the activation of gelatinase A. As a result of their range of activities, MMPs have been implicated in both normal and pathological structural remodelling processes such as embryogenesis, cell migration, tissue repair, and tumour necrosis. Their gene expression is tightly regulated by cytokines and growth factors that either enhance (IL-1, TNF $\alpha$, $\mathrm{TGF} \alpha$, EGF, FGF or PDGF) or inhibit (TGF $\beta$, IL-4) transcription. Furthermore, MMPs are secreted in a latent form and require cleavage to a truncated form to exert their proteolytic activity. ${ }^{12}$

Activated MMP-3 and MMP-9, in cleaving glycosaminoglycans side chains from proteoglycans, release stored growth factors such as basic fibroblast growth factor 2 (FGF-2) and transforming growth factor $\beta$ (TGF $\beta$ ), both of which have been co-localised within the airways to heparan sulphate containing proteoglycans and decorin, respectively. ${ }^{34}$ Other growth factors such as platelet derived growth factor (PDGF) and insulin-like growth factor (IGF), which have relevance to airway fibrosis, are also known to bind and be inactivated by proteoglycans. ${ }^{5}$ An understanding of the presence and localisation of MMPs within the airways is thus of pertinence to the understanding 
Table 1 Patient characteristics

\begin{tabular}{|c|c|c|c|c|c|c|}
\hline & Age & Sex & Atopy & $\begin{array}{l}F E V_{1} \\
\text { (litres) }\end{array}$ & $\begin{array}{l}F E V_{1} \\
\text { (\% pred) }\end{array}$ & $\begin{array}{l}P C_{20} \\
(m g / m l)\end{array}$ \\
\hline \multicolumn{7}{|c|}{ Healthy volunteers } \\
\hline 1 & 20 & $\mathrm{~F}$ & $\mathrm{~N}$ & 3.68 & 117.5 & $<16$ \\
\hline 2 & 19 & $\mathrm{~F}$ & $\mathrm{~N}$ & 3.80 & 100 & $>16$ \\
\hline 3 & 21 & $\mathrm{~F}$ & $\mathrm{~N}$ & 4.16 & 107 & $>16$ \\
\hline 4 & 21 & M & $\mathrm{N}$ & 4.67 & 101 & $>16$ \\
\hline 5 & 24 & $\mathrm{~F}$ & $\mathrm{~N}$ & 3.53 & 109 & $>16$ \\
\hline 6 & 26 & $\mathrm{~F}$ & $\mathrm{~N}$ & 4.24 & 115 & $>16$ \\
\hline 7 & 33 & M & $\mathrm{N}$ & 4.05 & 110 & $>16$ \\
\hline 8 & 21 & $\mathrm{~F}$ & $\mathrm{~N}$ & 3.57 & 107 & $>16$ \\
\hline Mean & 23.1 & & & 4.00 & 108.3 & $>16$ \\
\hline SD & 1.6 & & & 0.15 & 2.2 & \\
\hline \multicolumn{7}{|c|}{ Non-steroid treated asthmatics } \\
\hline 1 & 23 & M & $\mathrm{Y}$ & 2.18 & 51.9 & 0.16 \\
\hline 2 & 44 & $\mathrm{M}$ & $\mathrm{Y}$ & 2.50 & 70.9 & 0.093 \\
\hline 3 & 38 & M & $\mathrm{Y}$ & 2.65 & 61.4 & 0.05 \\
\hline 4 & 20 & M & $\mathrm{Y}$ & 2.45 & 75.1 & 0.45 \\
\hline 5 & 45 & M & $\mathrm{Y}$ & 4.15 & 94.2 & 0.03 \\
\hline 6 & 37 & M & $\mathrm{Y}$ & 4.05 & 87.5 & 0.63 \\
\hline 7 & 31 & M & $\mathrm{Y}$ & 3.75 & 84.6 & 0.72 \\
\hline 8 & 31 & $\mathrm{~F}$ & $\mathrm{Y}$ & 2.55 & 76.3 & 0.10 \\
\hline 9 & 28 & $\mathrm{~F}$ & $\mathrm{Y}$ & 2.9 & 86.6 & 0.05 \\
\hline Mean & 31 & & & 3.0 & 76.5 & 0.14 \\
\hline SD & 8.7 & & & 0.8 & 3.75 & $(0.04-0.46)$ \\
\hline \multicolumn{7}{|c|}{ Steroid treated asthmatics } \\
\hline 1 & 56 & $\mathrm{~F}$ & $\mathrm{~N}$ & 1.89 & 77.5 & 0.34 \\
\hline 2 & 60 & $\mathrm{~F}$ & $\mathrm{Y}$ & 0.83 & 40.3 & ND \\
\hline 3 & 64 & $\mathrm{~F}$ & $\mathrm{Y}$ & 0.97 & 41.8 & ND \\
\hline 4 & 36 & M & $\mathrm{N}$ & 1.85 & 50.4 & ND \\
\hline 5 & 55 & $\mathrm{~F}$ & $\mathrm{Y}$ & 1.12 & 39.7 & ND \\
\hline 6 & 33 & M & $\mathrm{N}$ & 2.78 & 65.9 & 0.87 \\
\hline 7 & 56 & M & $\mathrm{N}$ & 1.33 & 46.0 & ND \\
\hline 8 & 20 & $\mathrm{~F}$ & $\mathrm{Y}$ & 3.32 & 86.4 & 0.29 \\
\hline Mean & 47.5 & & & 1.76 & 56.0 & \\
\hline SD & 15.7 & & & 0.32 & 6.45 & \\
\hline
\end{tabular}

$\mathrm{PC}_{20}=$ geometric mean $+($ range $) ; \mathrm{ND}=$ not done.

of airway fibrosis, one of the structural contributors to airway wall thickening. Airway wall thickening has been mathematically linked to increased bronchial hyperresponsiveness (BHR), ${ }^{6}$ a physiological hallmark of the asthmatic process, and recent studies have specifically related the thickness of the subbasement membrane collagen to the level of BHR. These structural changes have also been implicated in the exaggerated progressive decline in lung function in asthma, a feature underlying the chronicity of disease. ${ }^{78}$

In view of the potential importance of the MMPs to the development of structural changes in the airways in asthma and the identification of inflammatory leucocytes as a potential source of MMP- $9,{ }^{9}$ we have used immunohistochemical staining in resin embedded tissue to explore the cellular localisation and distribution of MMP-3 and MMP-9 in patients with asthma of differing severity and in healthy controls.

\section{Methods}

SUBJECTS

Eight healthy non-atopic volunteers (two men) of mean (SD) age 23.1 (1.6) years and 17 asthmatic subjects subdivided into nine symptomatic subjects (seven men) of mean (SD) age 31.0 (8.7) years receiving salbutamol as their sole medication and eight steroid dependent, chronic, persistently symptomatic subjects (three men) of mean (SD) age 47.5 (15.7) years participated in the study. The clinical and physiological characteristics of the individuals are shown in table 1 . All of the chronic steroid dependent asthmatics were receiving inhaled steroids (median dose $2000 \mu \mathrm{g}$, range 1500-
$2000 \mu \mathrm{g}$ ) and also received bronchodilator medication as required. In addition, five of these subjects were receiving treatment with oral prednisolone in a dose of $5-40 \mathrm{mg}$ (median $15 \mathrm{mg}$ ).

All patients and volunteers underwent skin prick testing to common aeroallergens including Dermatophagoides pteronyssinus, Aspergillus fumigatus, grass pollen, cat fur, and dog hair (ALK, Denmark) as well as a positive (histamine) and negative (normal saline) control. A positive response was taken as a weal of $3 \mathrm{~mm}$ diameter or more than the negative control. Bronchial reactivity testing to histamine to determine the $\mathrm{PC}_{20}$ value was undertaken as previously described using a modification of the methods of Chai et al. ${ }^{10}$ All subjects were non-smokers and had no acute exacerbations requiring change in maintenance therapy in the eight weeks prior to the study.

The study was approved by the Southampton University and Hospitals joint ethics subcommittee and the participants gave written informed consent.

BRONCHOSCOPY AND TISSUE PROCESSING

Bronchoscopy was performed under local anaesthesia using an Olympus BFT20 fibreoptic bronchoscope (Olympus Company, Tokyo, Japan) as previously described ${ }^{11}$ and in accordance with current NHLBI guidelines. ${ }^{12}$ Thus, all subjects received nebulised salbutamol $5 \mathrm{mg}$ and ipratropium bromide $0.5 \mathrm{mg}$ prior to bronchoscopy and intravenous atropine $0.6 \mathrm{mg}$ and midazolam were administered to decrease secretions and to induce mild sedation, respectively. Topically applied lignocaine (1-10\%) was used to achieve local anaesthesia and $28 \%$ oxygen was administered via nasal cannulae during the procedure to maintain the $\mathrm{PaO}_{2}$. Haemoglobin oxygen saturation was monitored using an Ohmeda pulse oximeter. Bronchial biopsy specimens were obtained from the right middle lobe or apical segment of the lower lobe carinae using FB 15C biopsy forceps (Olympus Company). The biopsy specimen was immediately placed in ice cooled acetone containing the protease inhibitors iodoacetamide $(20 \mathrm{mM})$ and phenylmethyl sulphonyl fluoride ( $2 \mathrm{mM})$, left for fixation at $-20^{\circ} \mathrm{C}$ for $16-20$ hours and then processed into glycolmethacrylate (GMA) resin for embedding $^{13}$ prior to subsequent immunohistochemical assessment.

IMMUNOHISTOCHEMICAL ANALYSIS

Immunostaining of GMA-embedded tissue was performed using a technique described previously. ${ }^{13}$ Thin $(2 \mu \mathrm{m})$ sections were cut in duplicate, floated on $0.2 \%$ ammonia solution in water for one minute, and dried at room temperature for 1-4 hours. Sections were first treated with a solution of $0.1 \%$ sodium azide and $0.3 \%$ hydrogen peroxide to inhibit endogenous peroxidase. After three washes each of five minutes in Tris buffered saline (TBS), $\mathrm{pH}$ 7.6, blocking medium consisting of Dulbecco's modified Eagle's medium, $10 \%$ fetal calf serum, and $1 \%$ bovine serum albumin was applied for 30 minutes. Sections were then 
Table 2 Median (range) cell counts $/ \mathrm{mm}^{2}$ in the submucosa of the three groups of subjects

\begin{tabular}{lccc}
\hline & $\begin{array}{l}\text { Healthy volunteers } \\
(n=8)\end{array}$ & $\begin{array}{l}\text { Non-corticosteroid } \\
\text { treated asthma } \\
(n=9)\end{array}$ & $\begin{array}{l}\text { Corticosteroid treated } \\
\text { asthma } \\
(n=8)\end{array}$ \\
\hline MMP-9 & $5.9(0-34.4)$ & $6.6(1.1-14.5)$ & $8.6(3.9-19.9)$ \\
MMP-3 & $0.0(0-0.3)$ & $0.0(0-4.8)$ & $0.0(0-6.9)$ \\
AA1 & $34.5(27-98)$ & $20.8(9.3-63.6)$ & $68.0(6.7-83.5)$ \\
EG2 & $0.8(0-5.8)$ & $18.5(5.7-98.0)^{\star}$ & $9.0(2.3-23)^{\star}$ \\
NOE & $31.0(2.8-112)$ & $26.0(2.5-381)$ & $41.7(1.8-75)$ \\
${ }^{\star} \mathrm{p}<0.01$. & & &
\end{tabular}

incubated with the primary antibody for 16-20 hours using monoclonal antibodies and one hour for polyclonal antibodies. The following mouse $\operatorname{IgG}_{1}$ monoclonal antibodies were used: AA1 to mast cell tryptase (Dr A Walls, Southampton University, Southampton, UK); EG2 to the cleaved form of ECP in activated eosinophils (Pharmacia-Upjohn, Milton Keynes, UK); anti-human neutrophil elastase (NOE) (Dako Ltd, High Wycombe, UK). Bound antibodies were then labelled with biotinylated rabbit anti-mouse Fab fragments (Dako Ltd, High Wycombe, UK) during a two hour incubation and demonstrated using the streptavidin-biotin-peroxidase detection system (Dako Ltd). Polyclonal rabbit anti-human antibodies were used for immunostaining of both the latent and the active forms of MMP-3 and MMP-9 (Biogenesis, Poole, UK). The secondary antibody, biotinylated swine antiserum to rabbit Fab fragments (Dako Ltd, High Wycombe, UK), was applied for one hour. Aminoethylcarbazole was used as the chromogen and the sections were counterstained with Mayer's haematoxylin. Control sections were always stained in parallel with the primary antibody omitted. According to the suppliers, the MMP antibodies do not cross react with other MMPs in immunohistochemical analysis. In addition, the specificity of the polyclonal antibodies to MMP-3 and MMP-9 was further demonstrated by immunostaining of Western blots of $50 \mathrm{ng}$ each of MMP-3 and MMP-9 antigen (Biogenesis, Poole, UK) which were detected only by the appropriate MMPspecific antibody.

ASSESSMENT AND QUANTITATION OF

IMMUNOHISTOCHEMICAL STAINING

The total number of cells within the submucosa exhibiting positive immunoreactivity for the MMPs AA1, EG2 and neutrophil elastase were counted using light microscopy at $\times 400$ and then related to the total submucosal area with the exclusion of muscle and glands, as measured by a computer assisted image analysis system (Apple Macintosh Quadra 700 com- puter; colourVision 1.6 software, Improvision, Coventry, UK), and the results presented as cells $/ \mathrm{mm}^{2}$. Cell counts within the epithelium were not assessed since only occasional cells positive for MMPs were observed in this compartment.

Immunoreactivity for MMP-3 and MMP-9 was co-localised using the Camera Lucida system (Leica UK Ltd, Milton Keynes, UK) as previously described ${ }^{14}$ with adjacent sections separately stained for tryptase, EG2, and NOE to delineate mast cells, eosinophils, and neutrophils, respectively. Six biopsy specimens for MMP-9 and three for MMP-3 were used for analysis from the non-corticosteroid treated group of asthmatic subjects in whom there were sufficient positive cells. At least three fields at $\times 10$ magnification were compared and an assessment of the proportion of each cell type immunostaining for each of MMP-9 and MMP-3 was derived.

Immunoreactivity for MMP-3 and MMP-9 in the submucosal extracellular matrix was assessed by two approaches. A computer assisted image analysis system was used in which two areas of each section (at $\times 400$ magnification) showing immunoreactivity were selected for measurements in each biopsy specimen. Muscles, glands, epithelium, and holes larger than $0.009 \mathrm{~mm}^{2}$ were excluded, yielding a size of the measured areas of $0.5-0.9 \mathrm{~mm}^{2}$. The evaluation of immunoreactivity was expressed as the area immunostained as a percentage of the total area and always included the subtraction of background staining measurements in the same areas of the corresponding control section. The extracellular immunostaining was further evaluated by ranking of photomicrographs $(\times 100$ magnification) and the two methods of assessments were compared. The ranking procedure was undertaken in a blinded approach by two observers who were unaware of the coding.

\section{STATISTICAL ANALYSIS}

Tissue quantities, cell counts, and measurement of extracellular matrix immunostaining were expressed as medians and ranges and comparison between groups was made using Kruskal-Wallis one way analysis of variance on ranks. A $p$ value of $<0.05$ was regarded as statistically significant. The two methods of assessing extracellular matrix immunostaining were compared using the Bland-Altman method $^{15}$ after converting the data derived from the image analysis into rank numbers.
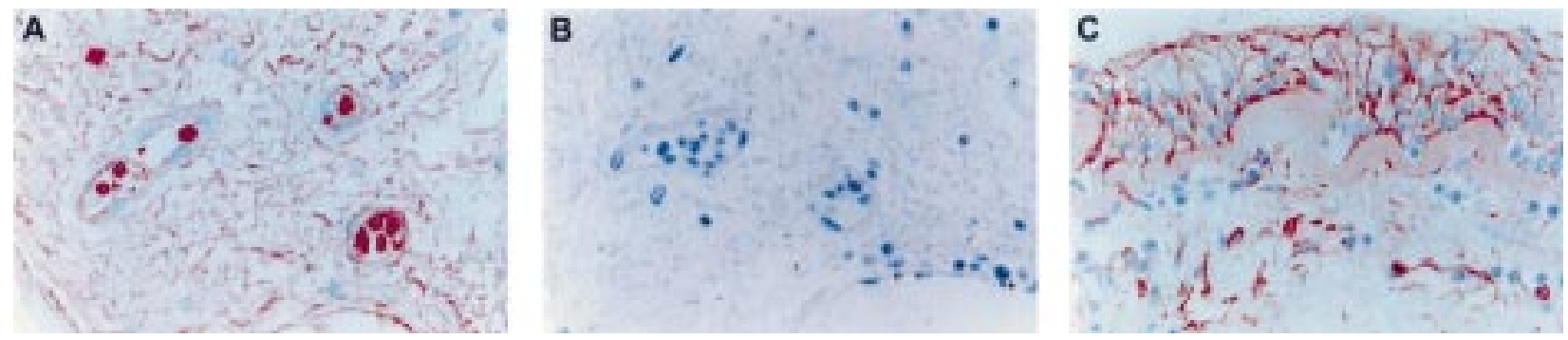

Figure 1 MMP-9 immunoreactivity in the bronchial submucosa from (A) a healthy subject (original magnification $\times 400)$ and (B) TBS control (original magnification $\times 400$ ); (C) MMP-3 immunoreactivity in bronchial tissue from a patient with severe asthma (original magnification $\times 400$ ). 

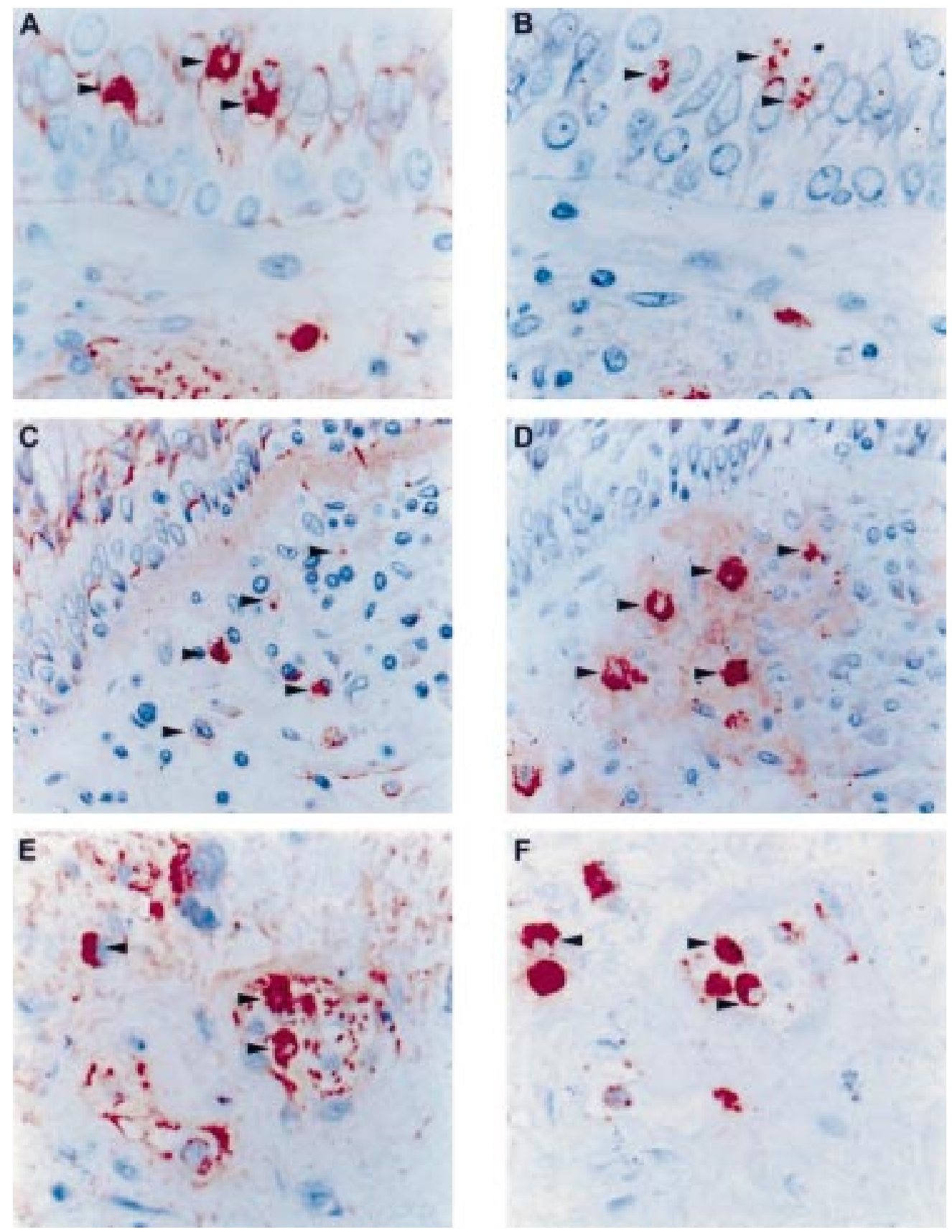

Figure 2 (A) MMP-9 and (B) neutrophil elastase immunoreactivity in sequential sections of bronchial tissue from a healthy subject (original magnification $\times 630$ ); (C) MMP-3 and (D) tryptase immunoreactivity in bronchial tissue from a subject with severe asthma (original magnification $\times 400$ ); (E) MMP-3 and (F) EG2 immunoreactivity in bronchial tissue from a subject with mild asthma (original magnification $\times 630$ ).

\section{Results}

PATIENT GROUPS

The resting airflow obstruction in the asthmatic groups was significantly lower than that in the healthy control group $(\mathrm{p}<0.01)$ and the degree of airflow obstruction was significantly greater in the patients with chronic persistent disease $(p<0.05)$ than in the non-steroid treated asthmatic group (table 1). Bronchial hyperresponsiveness was not present in the healthy group but was significantly increased in the mild asthmatic patients $(p<0.001)$ and in the three subjects with severe asthma in whom measurement was possible. Measurement of $\mathrm{PC}_{20}$ histamine values was not possible in five of the subjects in the severe group due to their inability to discontinue bronchodilator therapy or because of poor lung function.

\section{CELL IMMUNOREACTIVITY}

The biopsy specimens from the asthmatic subjects contained significantly more eosinophils per unit area than did the biopsy specimens from the healthy controls $(p<0.001)$, with no significant difference existing between the non-steroid treated and the steroid treated, but persistently symptomatic, groups. No differences existed between the three groups in submucosal mast cell or neutrophil numbers (table 2).

MMP-9 positive cells in the submucosa were present in both the extravascular and intravas- 
Table 3 MMP co-localisation in non-corticosteroid treated asthmatic subjects

\begin{tabular}{|c|c|c|c|c|c|c|}
\hline & \multicolumn{3}{|c|}{$\begin{array}{l}\% \text { of } M M P \text { positive cells } \\
\text { expressing cell specific markers }\end{array}$} & \multicolumn{3}{|c|}{$\%$ of specific cells expressing $M M P s$} \\
\hline & $A A 1$ & $E G 2$ & $N O E$ & $A A 1$ & $E G 2$ & $N O E$ \\
\hline MMP-3 $(\mathrm{n}=3)$ & $18(0-40)$ & $60(38-71)$ & $27(0-66)$ & $40(0-50)$ & $50(38-75)$ & $40(0-50)$ \\
\hline MMP-9 $(\mathrm{n}=6)$ & 0 & 0 & $59(29-86)$ & 0 & 0 & $40(20-57)$ \\
\hline
\end{tabular}

Values are median (range).

cular compartments (fig 1A), although a few cells were also observed within the epithelium (fig 2A). Co-localisation of immunoreactivity for MMP-9 and neutrophil elastase (fig 2A and B) showed that many MMP-9 containing cells were neutrophils. Within the submucosa of non-corticosteroid treated asthmatic subjects, $59 \%$ of MMP-9 positive cells were neutrophils (table 3). The identity of the remaining MMP-9 positive cells was not resolved, although they could not be co-localised to either mast cells or eosinophils. Platelets accounted for the punctate intravascular staining pattern, as we have subsequently shown platelets to be MMP-9 positive. There were no significant differences between the groups of subjects in the numbers of MMP-9 positive cells or neutrophils in the submucosa (table 2).

The number of MMP-3 positive cells in the submucosa was significantly lower than that for MMP-9 in all groups $(p<0.01)$ and there was no significant difference between the groups in the number of MMP-3 positive cells (table 2), all with a median number of zero. Colocalisation of MMP-3 with cell specific markers in a subset of non-corticosteroid treated asthmatic subjects in whom there were sufficient MMP-3 positive cells for this analysis demonstrated that eosinophils and tryptase positive mast cells together accounted for $78 \%$ of MMP-3 positive cells (table 3). MMP-3 immunoreactivity had a granular appearance in mast cells which, as indicated by the diffuse staining for tryptase in the surrounding matrix, were in an activated state (fig $2 \mathrm{C}$ and D). Eosinophils in both the intravascular and extravascular compartments stained positively for MMP-3 (fig 2E and F).

\section{MATRIX IMMUNOREACTIVITY}

The extent of matrix immunoreactivity was assessed by a computer assisted image analysis system and by rank scoring of the relative abundance of staining. Bland-Altman analysis of the data (table 4 ) showed that the $95 \%$ confidence interval for the difference in results was -2.38 to +2.38 which, being less than $10 \%$ of the total rankings, indicates good agreement between the methods.

Table 4 Extracellular matrix immunostaining in bronchial biopsy specimens

\begin{tabular}{|c|c|c|c|}
\hline & $\begin{array}{l}\text { Healthy volunteers } \\
(n=8)\end{array}$ & $\begin{array}{l}\text { Non-steroid treated } \\
\text { asthmatics }(n=9)\end{array}$ & $\begin{array}{l}\text { Steroid treated } \\
\text { asthmatics }(n=8)\end{array}$ \\
\hline \multicolumn{4}{|c|}{ Computer assisted image analysis stained area (\% of total) } \\
\hline MMP-9 & $0.38(0.07-2.21)$ & $0.16 \quad(0.02-0.48)$ & $1.12(0.02-3.54)$ \\
\hline MMP-3 & $0.0(0.0-0.39)$ & $0.004(0.0-0.39)$ & $0.17(0.0-1.49)$ \\
\hline \multicolumn{4}{|c|}{ Rank order analysis of photomicrographs } \\
\hline MMP-9 & $14 \quad(7-24)$ & $(1-19)$ & $(5-25)$ \\
\hline MMP-3 & $(0-12)$ & $(0-10)$ & $(0-16)$ \\
\hline
\end{tabular}

Values are median (range)
Immunoreactivity for MMP-9 (fig 1A) was evident in the extracellular matrix of the bronchial submucosa in all subject groups investigated in this study. Within the tissue matrix the staining had a distinctive wavy appearance (fig 1A). Extracellular staining was also evident in the bronchial epithelium and its associated basement membrane (fig 2A). There was, however, no immunoreactivity in the lamina reticularis (fig 2A). Controls in which the primary antibody was omitted showed no staining (fig 1B). Although matrix associated MMP-9 was strikingly more abundant in some patients with severe asthma, overall there was no significant difference between the groups (table 4). There was no significant correlation between the extent of MMP-9 matrix immunoreactivity and the submucosal MMP-9 positive cell count.

The extent of MMP-3 immunoreactivity in the extracellular matrix of the submucosa (fig 1C) was less than that for MMP-9 in all subject groups, but this difference was only statistically significant in the healthy subjects $(p<0.05)$. In the asthmatic subjects extracellular staining was clearly associated with the epithelium and with the thickened lamina reticularis, particularly in those with severe asthma (fig 1C). The increased shedding of the epithelium in asthma and the absence of a thickened lamina reticularis in normal subjects made statistical comparisons between groups impossible. As for MMP-9, there was no significant difference between the subject groups in the extent of MMP-3 matrix staining although subjects with severe asthma exhibited greater matrix immunoreactivity than the other two groups (table 4). The extent of extracellular matrix staining did not correlate with the submucosal count of MMP-3 positive cells.

\section{Discussion}

Using an immunohistochemical approach this study has investigated the abundance and distribution in bronchial tissue of MMP-9 and MMP-3. Distinct cellular localisation could be identified which co-localised MMP-3 to mast cells, eosinophils and neutrophils, whereas MMP-9 immunoreactivity was only evident in neutrophils with no apparent localisation to either mast cells or eosinophils. In addition, there was distinct evidence of extracellular matrix immunoreactivity. The immunoreactivity for MMP-3 was found adjacent to the epithelium in the lamina reticularis as well as in the submucosal matrix, whereas MMP-9 immunoreactivity was predominantly within the matrix. The extent of this matrix immunoreactivity was quantified by two separate 
methods which gave good concordance and did not reveal any significant difference between subjects with mild or severe asthma and normal subjects.

Mast cells and eosinophils are key effector cells in the asthmatic inflammatory response and this is the first report of the presence of MMP-3 in both of these cell types. It has been suggested that MMP-3 has important interactions with the tissue matrix, thereby linking allergic airway inflammation and airway remodelling in asthma. Substrates known to be degraded by MMP-3 include collagen IV and V, fibronectin, laminin, and elastin. ${ }^{16}$ In addition, MMP-3 is an effective proteoglycanase, ${ }^{1}$ cleaving the core protein of proteoglycans including perlecan. ${ }^{17}$ The cleavage of bound growth factors such as FGF-2 or TGF $\beta$ from proteoglycan storage sites would potentially contribute to fibroblast proliferation and the development of subepithelial fibrosis. In addition, MMPs have been reported to be involved in the bioprocessing of pro-TNF $\alpha$ in vitro. ${ }^{18}$ In this respect MMP-3 is more potent than MMP-9, and MMP inhibitors have been shown to block the release of TNF $\alpha$ in vivo. ${ }^{18}$ Since TNF $\alpha$ is localised to human lung mast cells, ${ }^{19}$ this creates the opportunity for MMP-3 to act potentially as an activator of $\mathrm{TNF} \alpha$ release, thereby enhancing the profibrotic course and influencing endothelial cell activation and the recruitment of infiltrating leucocytes.

We have previously detected MMP-9 activity in peripheral blood eosinophils. ${ }^{20}$ Eosinophils have been reported to be a source of MMP-9 in airway inflammation in asthma, with a greater number expressing MMP-9 mRNA in biopsy specimens from asthmatic subjects than from normal subjects. ${ }^{21}$ There have, however, been no detailed immunohistochemical assessments of tissue MMP expression in asthma. Our failure to demonstrate immunolocalisation of MMP-9 to eosinophils is, however, consistent with the discrepancy identified by Ohno and colleagues in the mRNA and protein expression for MMP-9 in eosinophils in the bronchial submucosa of asthmatic subjects. Conversely, Ohno et $a l^{11}$ found that neutrophils were negative for MMP-9 mRNA while our analysis of intracellular MMP-9 indicated that the neutrophil is the most abundant MMP-9 positive cell type. Expression of gelatinase is a marker of terminal differentiation of neutrophils in the bone marrow, ${ }^{22}$ the protein being stored in distinct tertiary granules which are mobilised, in part, during in vivo exudation of neutrophils and not reformed. ${ }^{23}$ The presence of MMP-9 protein in neutrophils but not mRNA is thus understandable. Conversely, it is conceivable that the absence of MMP-9 protein in eosinophils is a reflection of its complete release from these cells during extravasation despite their continuing mRNA expression. In support of this concept is the suggestion that MMP-9 plays a central role in eosinophil migration across basement membranes. ${ }^{24} \mathrm{~A}$ role for this enzyme in the effective transmigration of $\mathrm{T}$ cells ${ }^{25}$ and neutrophils ${ }^{26}$ has also been proposed, although recent studies using gelatinase $\mathrm{B}$ knockout mice indicate that gelatinase
B deficiency does not impair neutrophil migration in vivo. ${ }^{27}$ While the roles of MMP-9 in vivo remain largely undetermined, its deposition in the extracellular matrix characterises a number of inflammatory diseases including bullous pemphigoid in which the punctate staining of the extracellular space around weakly staining cells has been taken as indicative of eosinophil activation and enzyme secretion. ${ }^{28}$

Like MMP-3, MMP-9 is also known to bind to a number of matrix components. MMP-9 binds to type I and IV collagens, gelatin, and laminin ${ }^{29}$ while substrates for MMP-9 include type IV collagen, elastin, and proteoglycan ${ }^{17}$ but not type 1 collagen. The staining pattern for MMP-9 in the bronchial submucosa (fig 1A) suggests that this enzyme is bound by bundles of type I collagen, fibrils which are abundant in the matrix but relatively less so in the lamina reticularis which is enriched by types III and V collagen in asthma. ${ }^{30}$ Binding of MMP-9 to the collagenous matrix is proposed to confer retention, stability, and bioactivity for prolonged periods, facilitating its role in pericellular proteolysis. ${ }^{16}$ The binding characteristics for the gelatinases differ completely from those of stromelysin and stromelysin does not compete with gelatinase for collagen binding sites, thus MMP-9 is able to co-localise with MMP-3 on collagen. Both these MMPs exist in inactive pro-forms as well as in an activated state. Active MMP-3 is known to convert MMP-9 from its inactive to the active state. ${ }^{2}$ As the antibodies available do not distinguish between pro-MMP and active MMP, immunoreactivity does not identify the state of enzyme activation and it is, perhaps, not surprising that no clear differences are apparent in this respect between the disease and non-disease groups. Furthermore, because of the inability to distinguish between active and inactive forms of MMPs it is not possible to identify the effect of corticosteroids on the state of activation of MMPs in vivo by immunohistochemical analysis. Corticosteroids have been reported to suppress MMP expression in vitro ${ }^{1}$ although they fail to modify MMP release from macrophages in vivo. ${ }^{31}$

The extent of matrix immunoreactivity was assessed by two separate methods: computerised image analysis and comparative ranking of photomicrographs. Our analyses indicate that scoring and ranking by eye the degree of matrix immunoreactivity in tissues through assessment of photomicrographs is as valid as using the more sophisticated method of computer assisted image analysis of stained tissue sections. There was good agreement between the two methods of assessment.

This study therefore identifies the presence of MMP-3 and MMP-9 in the airways of subjects with asthma, together with co-localisation to cells of relevance to the disease processnamely, mast cells, neutrophils, and eosinophils; it also demonstrates the presence of these proteinases at differing sites within the extracellular matrix. Dynamic assessments of release along with alternative approaches to identify active MMPs will provide further information to understand the relevance of 
these findings in relation to clinical disease development. The authors are grateful to Mrs Carol Martin for typing the
manuscript. The work and Dr Shute were funded by the Medimanuscript. The work and Dr Shute were funded by the Medical Research Council of Great Britain while Dr Dahlen was
supported by grants from the Karolinska Institute, the Swedish supported by grants from the Karolinska Institute, the Swedish Care Sciences and Allergy Research.

1 Birkedal-Hansen H, Moore WGI, Bodden MK, et al. Matrix metalloproteinase: a review. Crit Rev Oral Biol Med metalloproteinase:

2 Ogata Y, Enghild JJ, Nagase H. Matrix metalloproteinase 3 (stromelysin) activates the precursor for the human matrix metalloproteinase 9. F Biol Chem 1992;267:3581-4.

3 Redington AE, Roche WE, Holgate ST, et al. Colocalisation of immunoreactive transforming growth factor- $\beta 1$ and decorin in bronchial biopsies from asthmatic and normal subjects. F Pathol 1999 (in press).

4 Redington AE, Madden J, Frew AJ, et al. Basic fibroblast growth factor in asthma: Immunolocalisation in bronchia biopsies and measurement in bronchoalveolar lavage fluid at baseline and following allergen challenge. Am $\mathcal{F}$ Respir Crit Care Med 1995;151:A702.

5 Taipale J, Keski-oja J. Growth factors in the extracellular matrix. FASEB f 1997;11:51-9.

6 Wiggs BR, Boskn C, Pare PD, et al. A model of airway narrowing in asthma and in chronic obstructive pulmonary disease. Am Rev Respir Dis 1992;145:1251-8.

7 Peat JK, Woolcock AJ, Cullen K. Rate of decline of lung function in subjects with asthma. Eur $\mathcal{F}$ Respir Dis 1987;70 $171-9$

8 Ulrik CS, Backer V, Dirksen A. A 10 year follow up of 180 adults with bronchial asthma: factors important fo the decline in lung function. Thorax 1992;47:14-8.

9 Goetzl EJ, Banda MJ, Leppert D. Matrix metalloproteinases in immunity. F Immunol 1996;156:1-4.

10 Chai H, Farr RS, Froehlich LA, et al. Standardisation of bronchial inhalation challenge procedures. 7 Allergy Clin Immunol 1975;56:323-7.

11 Djukanovic R, Wilson JW, Lai CKW, et al. The safety aspects of fibreoptic bronchoscopy, bronchoalveolar lavage and endobronchial biopsy in asthma. Am Rev Respir Dis 1991;143:772-7.

12 National Heart, Lung and Blood Institute. Workshop summary and guidelines: investigative use of bronchoscopy, mary and guidelines: investigative use of bronchoscopy, diseases. F Allergy Clin Immunol 1992;88:808-14.

13 Britten KM, Howarth PH, Roche WR. Immunohistochemistry on resin sections: a comparison of resin embedding techniques for small mucosal biopsies. Biotech Histochem 1993;68:271-80.

14 Bradding P, Feather IH, Wilson S, et al. Immunolocalisation of cytokines in the nasal mucosa of normal and perennia rhinitic subjects: the mast cell as a source of IL-4, IL-5 and L-6 in human allergic mucosal inflammation. $\mathcal{F}$ Immuno 1993;151:3853-65.
15 Bland JM, Altman DG. Statistical methods for assessing agreement between two methods of clinical measurement. Lancet 1986;i:307-10.

16 Murphy G, Cockett MI, Ward RV, et al. Matrix metalloproteinase degradation of elastin, type IV collagen and proteoglycan. Biochem f 1991;277:277-9.

17 Whitelock JM, Murdoch AD, Iozzo RV. The degradation of human endothelial cell-derived perlecan and release of bound basic fibroblast growth factor by stromelysin, collagenase, plasmin and heparanases. F Biol Chem 1996;271:
10079-86.

18 Gearing AJH, Beckett P, Christodoulou M, et al. Processing of tumour necrosis factor- $\alpha$ precursor by metalloproteinases. Nature 1994;370:555-7.

19 Bradding P, Roberts JA, Britten KM, et al. Interleukins (IL) $-4,-5,-6$ and TNF $\alpha$ in normal and asthmatic airways: evidence for the human mast cell as an important source of evidence for the human mast cell as an important source of

20 Shute JK, Parmar J, Holgate ST, et al. Urinary GAG levels are increased in acute severe asthma: a role for eosinophil are increased in acute severe asthma: a role for eosinop

21 Ohno I, Ohtani H, Nitta Y, et al. Eosinophils as a source of matrix metalloproteinase-9 in asthmatic airway inflammation. Am F Respir Cell Mol Biol 1997;16:212-9.

22 Borregaard N, Sehested M, Nielson BS, et al. Biosynthesis of granule proteins in normal human bone marrow cells. Gelatinase is a marker of terminal neutrophil differentiation. Blood 1995;85:812-7.

23 Sengelov H, Follin P, Kjeldsen L, et al. Mobilization of granules and secretory vesicles during in vivo exudation of human neutrophils. F Immunol 1995; 154:4157-65.

24 Okada S, Kita H, George TJ, et al. Migration of eosinophils through basement membrane components in vitro: role of through basement membrane components in vitro: role of
matrix metalloproteinase-9. Am 7 Respir Cell Mol Biol matrix metalloprote.

25 Xia M, Leppert D, Hauser SL, et al. Stimulus specificity of matrix metalloproteinases dependence of human $\mathrm{T}$ cell migration through a model basement membrane. F Immunol 1996;156:161-7.

26 Delclaux C, Delacourt C, d'Ortho M-P, et al. Role of gelatinase $\mathrm{B}$ and elastase in human polymorphonuclear neutrophil migration across membrane. Am $\mathcal{F}$ Respir Cell Miol Biol 1996;14:288-95.

27 Betsuvaku J, Shipley M, Liu F, et al. Gelatinase B deficiency does not impair neutrophil migration in vivo. Am f Respir Crit Care Med 1998;157:A26.

28 Stahle-Backdahl M, Inoue M, Giudice GJ, et al. 92-kD gelatinase is produced by eosinophils at the site of blister formation in bullous pemphigoid and cleaves the extracellular domain of recombinant $180-\mathrm{kD}$ bullous pemphigold autoantigen. 7 Clin Invest 1994;93:2022-30.

29 Allan JA, Docherty AJP, Barker PJ, et al. Binding of gelatinase A and B to type-I collagen and other matric gelatinase A and B to type-I collagen an
components. Biochem 7 1995;309:299-306.

30 Roche WR, Beasley R, Williams JH, et al. Subepithelial fibrosis in the bronchi of asthmatics. Lancet 1989; i:520-4.

31 Mautino G, Oliver N, Chanez P, et al. Increased release of matrix metalloproteinase-9 in bronchoalveolar lavage fluid and by alveolar macrophages of asthmatics. Am $\mathcal{F}$ Respir Cell Mol Biol 1997;17:583-91. 